\title{
Fermi level pinning induced electrostatic fields and band bending at organic heterojunctions
}

\author{
K. Akaike, ${ }^{1, a)}$ N. Koch ${ }^{1,2}$ and M. Oehzelt ${ }^{1,2}$ \\ ${ }^{1}$ Institut für Physik \& IRIS Adlershof, Humboldt-Universität zu Berlin, Brook-Taylor-Str. 6, 12489 Berlin, \\ Germany \\ ${ }^{2}$ Helmholtz-Zentrum Berlin für Materialien und Energie GmbH, Albert-Einstein-Str. 15, 12489 Berlin, \\ Germany \\ a) Electronic mail: kakaike@physik.hu-berlin.de
}

\begin{abstract}
The energy level alignment at interfaces between organic semiconductors is of direct relevance to understand charge carrier generation and recombination in organic electronic devices. Commonly, work function changes observed upon interface formation are interpreted as interface dipoles. In this study, using ultraviolet and X-ray photoelectron spectroscopy, complemented by electrostatic calculations, we find a huge work function decrease of up to $1.4 \mathrm{eV}$ at the $\mathrm{C}_{60}$ (bottom layer)/zinc phthalocyanine ( $\mathrm{ZnPc}$, top layer) interface prepared on a molybdenum trioxide $\left(\mathrm{MoO}_{3}\right)$ substrate. However, detailed measurements of the energy level shifts and electrostatic calculations reveal that no interface dipole occurs. Instead, upon $\mathrm{ZnPc}$ deposition, a linear electrostatic potential gradient is generated across the $\mathrm{C}_{60}$ layer due to Fermi level pinning of $\mathrm{ZnPc}$ on the high work function $\mathrm{C}_{60} / \mathrm{MoO}_{3}$ substrate, and associated band-bending within the $\mathrm{ZnPc}$ layer. This finding is generally of importance for understanding organic heterojunctions when Fermi level pinning is involved, as induced electrostatic fields alter the energy level alignment significantly.
\end{abstract}


The energy level alignment at organic and molecular semiconductor heterojunctions is generally recognized to be essential for the function and performance of organic electroluminescent ${ }^{1,2}$ and photovoltaic devices. ${ }^{3,4}$ Because of its direct relevance for understanding the underlying fundamental mechanisms, such as charge carrier recombination and generation, ${ }^{5-7}$ the energy level alignment at these interfaces has been extensively studied by ultraviolet and X-ray photoelectron spectroscopy (UPS and XPS, respectively). ${ }^{8-11}$ Due to the weak van der Waals interaction between the organic materials, Schottky-Mott-limit like behavior is often assumed ${ }^{12}$ with vacuum level alignment (VLA) across the interface, i.e., a constant electrostatic potential. Nevertheless, for numerous organic semiconductor combinations deviations from VLA were observed, e.g., bathocuproine (BCP)/3,4,9,10-perylenetetracarboxylicdianhydride (PTCDA) ${ }^{13}$ and 4,4',4"-tris[3-methyl-phenyl(phenyl)amino]-triphenylamine (m-MTDATA)/4,4'-N,N-dicarbazolyl-biphenyl (CBP). ${ }^{14}$ The shift of the vacuum level (measured as work function change) at the interfaces is generally attributed to the formation of an interface dipole. Several explanations for this have been put forward, ranging from molecular quadrupoles, ${ }^{15}$ interface charge transfer involving induced density of interface states, ${ }^{9}$ to molecular polaronic levels, ${ }^{10}$ or tailing of the density of states into the energy gap of the semiconductor films. ${ }^{16}$

In this contribution, we demonstrate that for the molecular heterojunction $\mathrm{C}_{60}$ (bottom layer) / zinc phthalocyanine ( $\mathrm{ZnPc}$, top layer) formed on molybdenum trioxide $\left(\mathrm{MoO}_{3}\right)$-covered gold, the shift in the vacuum level is caused by the highest occupied 
molecular orbital (HOMO) level pinning ${ }^{17}$ of the top organic layer. The charges transferred to the top layer due to pinning induce an electric field across the bottom layer, which mimics - in the sequence of measurements with increasing thickness - an interface dipole. This mechanism was identified by determining the electronic structure at the $\mathrm{C}_{60} / \mathrm{ZnPc}$ interface with UPS/XPS measurements and corresponding electrostatic calculations.

The $\mathrm{Au} / \mathrm{MoO}_{3} / \mathrm{C}_{60} / \mathrm{ZnPc}$ heterostructure was grown in a preparation chamber (base pressure $<5 \times 10^{-8}$ mbar). Prior to the deposition of the heterostructure, the $\mathrm{Au}(111)$ crystal was cleaned by repeated $\mathrm{Ar}$ ion sputtering $(1 \mathrm{keV}, \sim 1 \mu \mathrm{A})$ and annealing $(\sim 500$ ${ }^{\circ} \mathrm{C}$ ) cycles. The surface cleanliness was confirmed by the appearance of the surface state in the UPS spectrum [Fig. S1(a), supplemental material]. ${ }^{18}$ Then $2 \mathrm{~nm} \mathrm{MoO}_{3}$ was deposited to increase the sample work function from initially $5.4 \mathrm{eV}$ to $6.7 \mathrm{eV}$ (see Fig. 1a). The organic heterostructure comprised a $12 \mathrm{~nm} \mathrm{C}_{60}$ bottom layer, and was completed by evaporating ZnPc on top. The ZnPc layer was deposited in several steps, in order to determine the evolution of the energy level alignment at the organic/organic interface. UPS/XPS spectra were taken for each step in an analysis chamber (base pressure $<4 \times 10^{-9}$ mbar) interconnected to the evaporation chamber, with $\mathrm{He}_{\alpha}(21.22$ $\mathrm{eV}$, UPS) and $\mathrm{Al} \mathrm{K} \mathrm{K}_{\alpha}(1486.7 \mathrm{eV}, \mathrm{XPS})$ excitation energies, respectively. $\mathrm{He} \mathrm{I}_{\beta}$ - and $\mathrm{He} \mathrm{I}_{\gamma}$ satellites are already subtracted from the UPS spectra presented here. The sample work function (Wf) was inferred from the secondary electron cutoff (SECO) spectra, recorded 
with a DC sample bias of $-10.0 \mathrm{~V}$. In the main text we focus on the valence electronic structure, while the corresponding XPS spectra can be found in the supplemental material [Fig. S1]. ${ }^{18}$

On a freshly prepared $\mathrm{MoO}_{3}$ substrate, with a Wf of $6.7 \mathrm{eV}$, a $12 \mathrm{~nm}$ thick $\mathrm{C}_{60}$ layer was deposited. As a result, the sample Wf decreased to $6.0 \mathrm{eV}$ [see Fig. 1(a)]. As previously reported, ${ }^{19}$ this is rationalized in terms of Fermi level pinning of the $\mathrm{C}_{60}$ HOMO levels (ionization potential $=6.4 \mathrm{eV}^{17}$ ). Due to this pinning of the occupied states, electrons are transferred from $\mathrm{C}_{60}$ to the substrate to establish thermodynamic equilibrium. $^{20}$ The occupied levels, as measured with UPS, are shown in Fig. 1(b), where only the spectral signature of $\mathrm{C}_{60}$ is visible (at the bottom), indicating that the surface of $\mathrm{MoO}_{3}$ is fully covered. For the $12 \mathrm{~nm}$ thick $\mathrm{C}_{60}$ film the density of charged molecules at the surface is too low to be visible in the UPS spectrum. ${ }^{21}$

The organic heterostructure was then built by evaporating $\mathrm{ZnPc}$ onto the $\mathrm{C}_{60}$ layer. In Fig. 1(a) a further reduction of the Wf upon $\mathrm{ZnPc}$ deposition to a final value of 4.6 $\mathrm{eV}$ is apparent. In the valence region [Fig. 1(b)], a continuous change from the spectral signature of $\mathrm{C}_{60}$ towards $\mathrm{ZnPc}$ can be observed. Additionally, Fig. 1(b) shows that the $\mathrm{ZnPc} \mathrm{HOMO}$ level is close to zero binding energy (BE) and gradually shifts towards higher BE as a function of increasing thickness. This is highlighted in Fig. 1(c), where only the region close to the Fermi level is depicted. Up to a thickness of $1 \mathrm{~nm} \mathrm{ZnPc}$, where the $\mathrm{C}_{60}$ spectral signature can still be distinguished, a gradual shift of also the $\mathrm{C}_{60}$ 
features towards higher BE by up to $\sim 0.9 \mathrm{eV}$ is evident. The continuous reduction of the Wf, together with the shift of the ZnPc levels towards higher BE, is again a clear signature of HOMO level pinning. As the ionization potential of $\mathrm{ZnPc}(4.8 \mathrm{eV})$ is lower than the Wf of the $\mathrm{C}_{60}$-covered $\mathrm{MoO}_{3} / \mathrm{Au}$ substrate and therefore, as in the case of $\mathrm{C}_{60}$ on $\mathrm{MoO}_{3}$, electrons are removed from the $\mathrm{ZnPc}$ layer. In principle two scenarios are plausible, either the charges are transferred to the $\mathrm{C}_{60}$ layer, producing an interface dipole, or the charges are transferred all the way through the film to the metal substrate. If we assume an interface dipole to be formed, $25 \%$ of the molecules have to be charged to produce the full Wf shift observed (for the calculation, see the supplemental materials). ${ }^{18}$ In this case, in the UPS spectrum clearly charged and neutral molecules should be both visible. ${ }^{21-23}$ On the other hand, if we assume the charges to be located in the metal substrate, only as little as $1 \%$ of the molecules have to be charged to account for the Wf shift. This is because the individual dipole moments are way bigger due to the increased distance of the charges forming them. This fraction of charged molecules is too small to be seen in the UPS spectrum [Fig. 1(b)].

Complementary XPS measurements are fully in line with the UPS results and are discussed in detail in the supplemental materials [Fig. S2]. ${ }^{18}$ Also in the XPS spectra no signs of charged molecules are visible at the heterojunction interface. A summary of all core level peak position shifts is shown in Fig. 1(d). Gradual shifts towards higher BE are observed for the $\mathrm{ZnPc}$ levels starting from $0.5 \mathrm{~nm}$, where peak positions could be reliably determined (all peaks shift in parallel). The full range of the shift caused by 
$\mathrm{ZnPc}$ cannot be measured because the reference position is that without $\mathrm{ZnPc}$. Therefore, at a layer thickness of $0.5 \mathrm{~nm}$, the $\mathrm{ZnPc}$ already experiences the shifted $\mathrm{Wf}$ (cause by $\mathrm{ZnPc}$ itself) of $\sim 0.9 \mathrm{eV}$. Alas, to the measured shift, the Wf reduction has to be added. Nevertheless, the subsequent shifts follow, as expected, the general trend of the Wf reduction. Noteworthy, the apparent shift of the $\mathrm{C}_{60}$ core level (max. $\sim 0.9 \mathrm{eV}$ ) appears significantly larger, because the $\mathrm{C}_{60}$ shifts can be followed already from the very first $\mathrm{ZnPc}$ deposition, but the overall shift is still smaller than the final Wf reduction of 1.4 eV. Analogous arguments explain the difference in the maximum shifts of the HOMO levels of $\mathrm{C}_{60}$ and ZnPc in Figs. 1(b) and (c).

To rationalize the energy level alignment at this heterointerface and the underlying mechanism, and, in particular, where the charges from $\mathrm{ZnPc}$ are transferred to, electrostatic calculations were carried out within a recently reported framework. ${ }^{20}$ Briefly, in this model, the metal substrate is regarded as an infinite electron reservoir with a constant chemical potential. $\mathrm{MoO}_{3}$ is treated as an insulator with a dielectric constant of $\varepsilon_{\mathrm{r}}=14 .^{24}$ The density of states (DOS) of the organic layers are approximated by Gaussian peaks (representing their frontier orbital levels) and, initially assuming VLA, are occupied according to Fermi-Dirac-statistics. The resulting charge density is then used to solve the one-dimensional Poisson-equation, which yields the electrostatic potential across the $\mathrm{MoO}_{3} / \mathrm{C}_{60} / \mathrm{ZnPc}$ heterostructure. Then, the charge density is calculated again with the molecular DOS shifted in each layer according to the new electrostatic potential. These calculations are repeated self-consistently until a stationary 
solution is obtained. A detailed list of the material parameters used here can be found in the supplemental material. ${ }^{18}$

The calculated electron potential across the heterostructure $\mathrm{Au}(111) / \mathrm{MoO}_{3} / \mathrm{C}_{60}$ and a series of $\mathrm{ZnPc}$ thicknesses $(0-4 \mathrm{~nm})$ are shown in Fig. 2(a) (black curves, and green dots) together with the measured changes of the Wf (red crosses). The agreement between simulation and experiment is remarkable. We note that the calculation (black lines) shows the electron potential within the $\mathrm{C}_{60}$ film, while with UPS, due to its surface sensitivity, only the electrostatic potential of the surface region can be measured. Therefore, only the end-points of the calculated electrostatic potential curves (green dots) should be directly compared with experiment. The topmost black curve shows the situation before the organic heterostructure is formed, i.e., of only the $\mathrm{C}_{60}$ film on $\mathrm{Au}(111) / \mathrm{MoO}_{3}$. Also here, the measured $\mathrm{MoO}_{3}$ Wf reduction by $-0.7 \mathrm{eV}$ upon $\mathrm{C}_{60}$ deposition is reproduced. With increasing $\mathrm{ZnPc}$ thickness [following the blue arrow in Fig. 2(a)], the Wf is further reduced, as discussed before, and again perfectly agrees with the measurements [Fig. 1(a)]. The shape of the electrostatic potential within the heterostructure (black lines) reveals that the largest fraction of the potential drops across the $\mathrm{C}_{60}$ layer, even though the reason for the overall $\mathrm{Wf}$ change is the pinning of the $\mathrm{ZnPc}$ layer on top. This perfectly agrees with the appreciable shift of $\mathrm{C}_{60}$ (cf. Fig. 1) of $\sim 0.9 \mathrm{eV}$, compared to the overall $1.4 \mathrm{eV} \mathrm{Wf}$ reduction. The smaller apparent shifts of the ZnPc [Fig. 1 (c) and (d)] can be now also understood by following the potential curve, starting from $0.5 \mathrm{~nm} \mathrm{ZnPc}$ thickness (the 4th measurement point), the thickness from 
which on the peak positions could be reliably determined. At this thickness the potential is already shifted by $\sim 0.9$ eV. Fig. 2(b) summarizes the measured (XPS - blue, UPS red) as well as the calculated (black and green) changes of $\mathrm{C}_{60}$ level BEs and potentials upon $\mathrm{ZnPc}$ deposition. Note that the calculated shift of the topmost layer of $\mathrm{C}_{60}$ is slightly overestimated compared to the measurement, even though the overall shape reproduces the experimental data. This discrepancy is most likely caused by the assumed perfect layer-by-layer growth mode in the model. ${ }^{20}$ In reality, the heterointerface will have a certain roughness. Taking this into account, by comparing the experimental data to a $\mathrm{C}_{60}$ layer below the interface, e.g. the third one as shown in Fig. 2(b) (black curve), results in perfect agreement between measurement and calculation.

In addition to the electrostatic potential, also the charge density distribution within the heterostructure is readily available from the calculations. In Fig. 2(c) the situation before (red dots) and after $\mathrm{ZnPc}$ deposition (blue squares) is compared. The charge density distribution can be understood as follows: $\mathrm{MoO}_{3}$ is free of charges (an insulator was assumed), in $\mathrm{C}_{60}$ at the interface to $\mathrm{MoO}_{3}$ holes are accumulated due to HOMO level pinning, followed by an approximately exponential decay of the hole density away from the interface due to band-bending. ${ }^{20}$ Qualitatively the same can be seen at the $\mathrm{C}_{60} / \mathrm{ZnPc}$ interface. Holes are accumulated within $\mathrm{ZnPc}$ due to HOMO level pinning, and the density decays with increasing distance from the interface. Additionally, the electric field across the $\mathrm{C}_{60}$ layer shifts all $\mathrm{C}_{60}$ levels further away from the Fermi level 
and therefore reduces the pinning at the $\mathrm{MoO}_{3} / \mathrm{C}_{60}$ interface. This reduced pinning results in a lower hole density in the $\mathrm{C}_{60}$ film when $\mathrm{ZnPc}$ is deposited. It is noted that electrons from both $\mathrm{ZnPc}$ and $\mathrm{C}_{60}$ are transferred to the metal substrate.

The overall energy level diagram across the $\mathrm{MoO}_{3} / \mathrm{C}_{60} / \mathrm{ZnPc}$ heterostructure is summarized in Fig. 3. The Fermi level pinning of the ZnPc layer (due to the high Wf of the $\mathrm{C}_{60}$ layer) induces an electrostatic potential drop across $\mathrm{C}_{60}$, and no localized interface dipole occurs at this interface, even though a huge shift of the vacuum level is measured.

In summary, the interface of $\mathrm{C}_{60} / \mathrm{ZnPc}$ on a high work function substrate $(6.7 \mathrm{eV})$ was studied by UPS/XPS and modelled by electrostatic calculations. The $\mathrm{C}_{60}$ molecules in the bottom layer of this heterostructure are HOMO level pinned due to their ionization potential of $6.4 \mathrm{eV}$, which reduces the work function to $6.0 \mathrm{eV}$. This pinning situation causes a fraction of the molecules to be charged with the majority of holes accumulated close to the interface to $\mathrm{MoO}_{3}$. These charges are the origin of the electric field that causes the band-bending within $\mathrm{C}_{60}$. Depositing $\mathrm{ZnPc}$ onto the $\mathrm{C}_{60}$ film leads to a further reduction of the work function to a final value of $4.6 \mathrm{eV}$. Also in this case, due to the ionization potential of $\mathrm{ZnPc}(4.8 \mathrm{eV})$ being lower than the underlying film work function $(6.0 \mathrm{eV}), \mathrm{ZnPc}$ is HOMO level pinned and a fraction of molecules is positively charged. In this case, the electric field due to excess charges not only causes band-bending within the $\mathrm{ZnPc}$ layer, but extends (linearly) across the $\mathrm{C}_{60}$ layer below. Consequently, not only the $\mathrm{ZnPc}$ states are shifted upon heterojunction formation, but 
also the ones of $\mathrm{C}_{60}$. Therefore, no abrupt interface dipole for the $\mathrm{C}_{60} / \mathrm{ZnPc}$ heterostructure is involved. It appears thus necessary to evaluate whether previously postulated interface dipoles at different organic and molecular heterointerfaces can be reinterpreted by Fermi level pinning and concurrent electrostatic fields.

K.A. acknowledges financial support by the Alexander von Humboldt foundation. The authors thank Georg Heimel for fruitful discussions, critical reading of the manuscript, and help in the development of the electrostatic model, as well as Patrick Amsalem for inspiring this study.

\section{Reference}

${ }^{1}$ S. T. Lee, Y. M. Wang, X. Y. Hou, and C. W. Tang, Appl. Phys. Lett. 74, 670 (1999).

${ }^{2}$ I-W. Wu, Y.-H. Chen, P.-S. Wang, C.-G. Wang, S.-H Hsu, and C.-I Wu, Appl. Phys. Lett. 96, 013301 (2010).

${ }^{3}$ A. Tada, Y. Geng, Q. Wei, K. Hashimoto, and K. Tajima, Nat. Mater. 10, 450 (2011).

${ }^{4}$ K. S. Nalwa, J. A. Carr, R. C. Mahadevapuram, H. K. Kodali, S. Bose, Y. Chen, J. W. Petrich, B. Ganapathysubramanian, and S. Chaudhary, Energy Environ. Sci. 5, 7042 (2012).

${ }^{5}$ A. Rao, P. C. Y. Chow, S. Gélinas, C. W. Schlenker, C.-Z. Li, H.-L. Yip, A. K.-Y. Jen, D. S. Ginger, and R. H. Friend, Nature 500, 435 (2013).

${ }^{6}$ K. Vandewal1, S. Albrecht, E. T. Hoke, K. R. Graham, J. Widmer, J. D. Douglas, M. 
Schubert, W. R. Mateker, J. T. Bloking, G. F. Burkhard, A. Sellinger, J. M. J. Fréchet, A. Amassian, M. K. Riede, M. D. McGehee, D. Neher, and A. Salleo, Nat. Mater. 13, 63 (2014).

${ }^{7}$ T. M. Burke and M. D. McGehee, Adv. Mater. 26, 1923 (2014).

${ }^{8}$ H. Ishii, K. Sugiyama, E. Ito, and K. Seki, Adv. Mater. 11, 605 (1999).

${ }^{9}$ J. Hwang, A. Wan, and A. Kahn, Mat. Sci. Eng. R 64, 1 (2009).

${ }^{10}$ S. Braun, W. R. Salaneck, and M. Fahlman, Adv. Mater. 21, 1450 (2009).

${ }^{11}$ J. X. Tang, K. M. Lau, C. S. Lee, and S. T. Lee, Appl. Phys. Lett. 88, 232103 (2006).

${ }^{12}$ S. Zhong, J. Q. Zhong, H. Y. Mao, J. L. Zhang, J. D. Lin, and W. Chen, Phys. Chem. Chem. Phys. 14, 14127 (2012).

${ }^{13}$ H. Vázquez, W. Gao, F. Flores, and A. Kahn, Phys. Rev. B 71, 041306 (2005).

${ }^{14}$ S. Braun, M. P. de Jong, W. Osikowicz, and W. R. Salaneck, Appl. Phys. Lett. 91, 202108 (2007).

${ }^{15}$ S. Verlaak, D. Beljonne, D. Cheyns, C. Rolin, M. Linares, F. Castet, J. Cornil, and P. Heremans, Adv. Funct. Mater. 19, 3809 (2009).

${ }^{16}$ H. Y. Mao, F. Bussolotti, D.-C. Qi, R. Wang, S. Kera, N. Ueno, A. T. S. Wee, and W. Chen, Org. Electron. 12, 534 (2011).

${ }^{17}$ A. Wilke, P. Amsalem, J. Frisch, B. Bröker, A. Vollmer, and N. Koch. Appl. Phys. Lett. 98, 123304 (2011).

${ }^{18}$ See supplemental material at [URL will be inserted by AIP] for UPS and XPS spectra of the $\mathrm{Au}(111)$ substrate, the $\mathrm{MoO}_{3}$ film and the $\mathrm{ZnPc} / \mathrm{C}_{60}$ interface, calculated fraction 
of charged molecules at the organic heterojunction and the methods of electrostatic potential calculations.

${ }^{19}$ Irfan, M. Zhang, H. Ding, C. W. Tang, and Y. Gao. Org. Electron. 12, 1588 (2011).

${ }^{20}$ M. Oehzelt, N. Koch, and G. Heimel, Nat. Commun. 5, 4174 (2014).

${ }^{21}$ H. Wang, P. Amsalem, G. Heimel, I. Salzmann, N. Koch, and M. Oehzelt, Adv. Mater. 26, 925 (2014).

${ }^{22}$ J. Niederhausen, P. Amsalem, A. Wilke, R. Schlensinger, S. Winkler, A. Vollmer, J. P. Rabe, and N. Koch, Phys. Rev. B 86, 081411(R) (2012).

${ }^{23}$ P. Amsalem, J. Niederhausen, A. Wilke, G. Heimel, R. Schlesinger, S. Winkler, A. Vollmer, J. P. Rabe, and N. Koch, Phys. Rev. B 87, 035440 (2013).

${ }^{24}$ M. Sayer and A. Mansingh, Phys. Rev. B 6, 4629-4643 (1972).

${ }^{25}$ Y. Tanaka, K. Kanai, Y. Ouchi, and K. Seki, Chem. Phys. Lett. 441, 63 (2007).

${ }^{26}$ S. H. Park, J. G. Jeong, H.-J. Kim, S.-H. Park, M.-H. Cho, S. W. Cho, Y. Yi, M. Y. Heo, and H. Sohn, Appl. Phys. Lett. 96, 013302 (2010). 
Figure captions

\begin{tabular}{|c|c|}
\hline Figure number & caption \\
\hline Figure 1 & $\begin{array}{l}\text { (a) Measured work function (secondary electron cutoffs, } \mathrm{SECO} \text { ) for } \\
\mathrm{Au}(111) \text { (green), } \mathrm{Au}(111) / 2 \mathrm{~nm} \mathrm{MoO}_{3} \text { (blue), } \mathrm{Au}(111) / 2 \mathrm{~nm} \mathrm{MoO}_{3} / 12 \\
\mathrm{~nm}_{60} \text { (red), as well as a series of } \mathrm{ZnPc} \text { thicknesses on top (black). (b) } \\
\text { Valence spectra for } \mathrm{C}_{60} \text { and a series of } \mathrm{ZnPc} \text { thicknesses [colors } \\
\text { correspond to (a)]. (c) Zoom-in on the region close to the Fermi level } \\
\text { from (b). A magnification for the lowest } \mathrm{ZnPc} \text { coverages is shown in } \\
\text { the inset. (d) Summary of the peak shifts measured with XPS. C } 1 \mathrm{~s} \text { for } \\
\mathrm{C}_{60} \text {, and } \mathrm{C} 1 \mathrm{~s}, \mathrm{~N} 1 \mathrm{~s} \text { and } \mathrm{Zn} 2 \mathrm{p}_{3 / 2} \text { for } \mathrm{ZnPc} \text {. The measured shifts for } \\
\mathrm{ZnPc} \text { are offset by } 0.94 \mathrm{eV} \text { to take the work function shift at } 0.5 \mathrm{~nm} \\
\text { into account. See text for details. }\end{array}$ \\
\hline Figure 2 & $\begin{array}{l}\text { (a) Measured (red crosses) and calculated (green dots) work function } \\
\text { values. Black lines correspond to the shift in the electron potential } \\
\text { energy within the respective layer. (b) Comparison of the } \mathrm{C}_{60} \mathrm{HOMO} \\
\text { level shift measured by UPS (red), the } \mathrm{C}_{60} \mathrm{C} \text { 1s shift measured by XPS } \\
\text { (blue), and the calculated electron potential shift of the topmost layer } \\
\text { (green) and the } 3^{\text {rd }} \mathrm{C}_{60} \text { layer below the interface (black). (c) Calculated } \\
\text { charge density distribution before (red) and after (blue) completion of } \\
\text { the heterostructure. }\end{array}$ \\
\hline Figure 3 & $\begin{array}{l}\text { Schematic energy level diagram ( } E \text { in } \mathrm{eV} \text { ) for the heterostructure } 2 \mathrm{~nm} \\
\mathrm{MoO}_{3} / 12 \mathrm{~nm} \mathrm{C} 60 / 4 \mathrm{~nm} \mathrm{nPc} \text { within the layers. } E_{\mathrm{F}} \text { is the Fermi level of } \\
\text { the substrate }\left[\mathrm{Au}(111) / 2 \mathrm{~nm} \mathrm{MoO}_{3} \text {, assuming a perfect insulator]. }\right. \\
\text { Energy gaps of } \mathrm{C}_{60} \text { and } \mathrm{ZnPc} \text { are taken from Refs. } 25 \text { and } 26 \text {, } \\
\text { respectively. }\end{array}$ \\
\hline
\end{tabular}


(a)

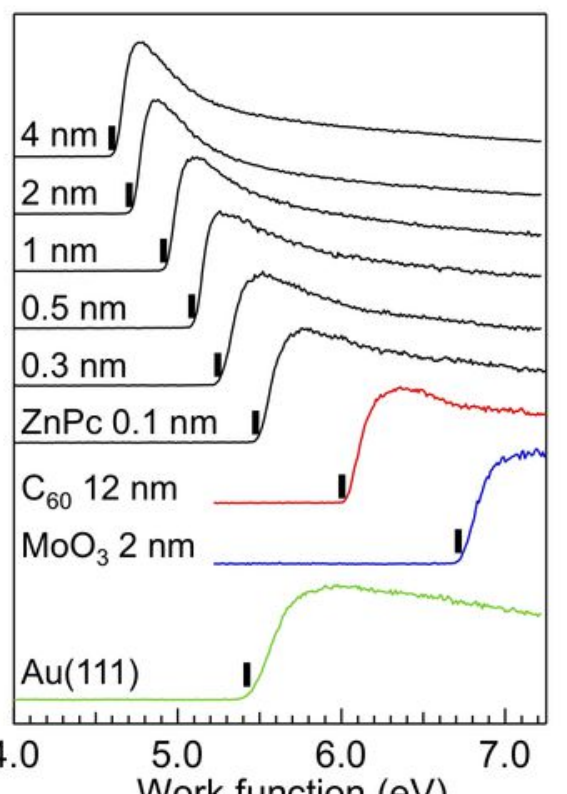

Work function $(\mathrm{eV})$ (b)

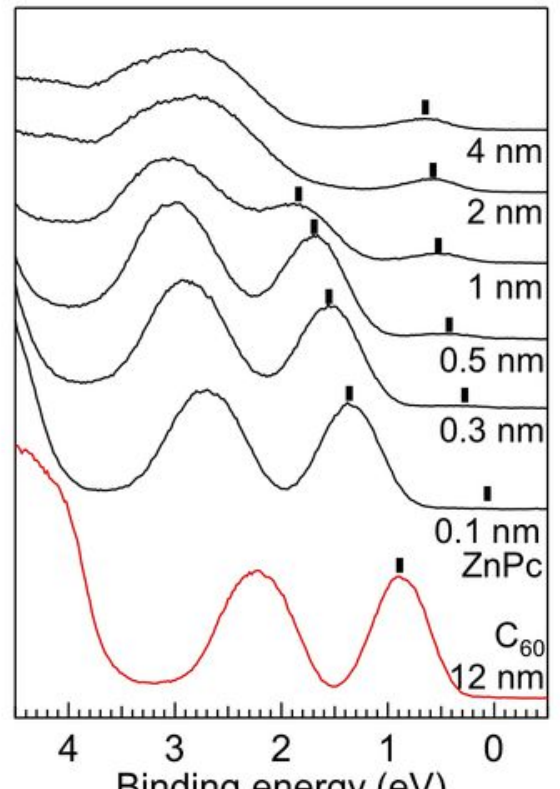

Binding energy $(\mathrm{eV})$ (c)

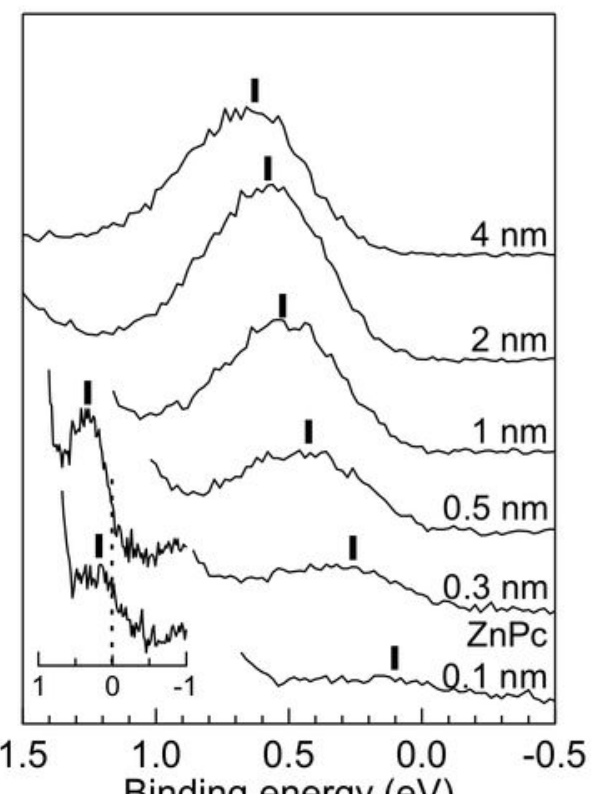

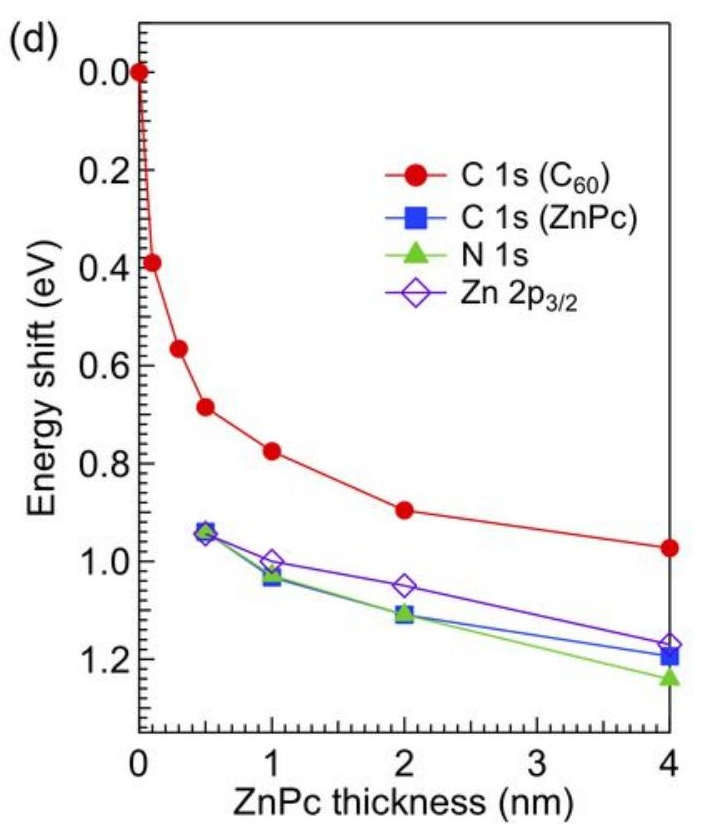



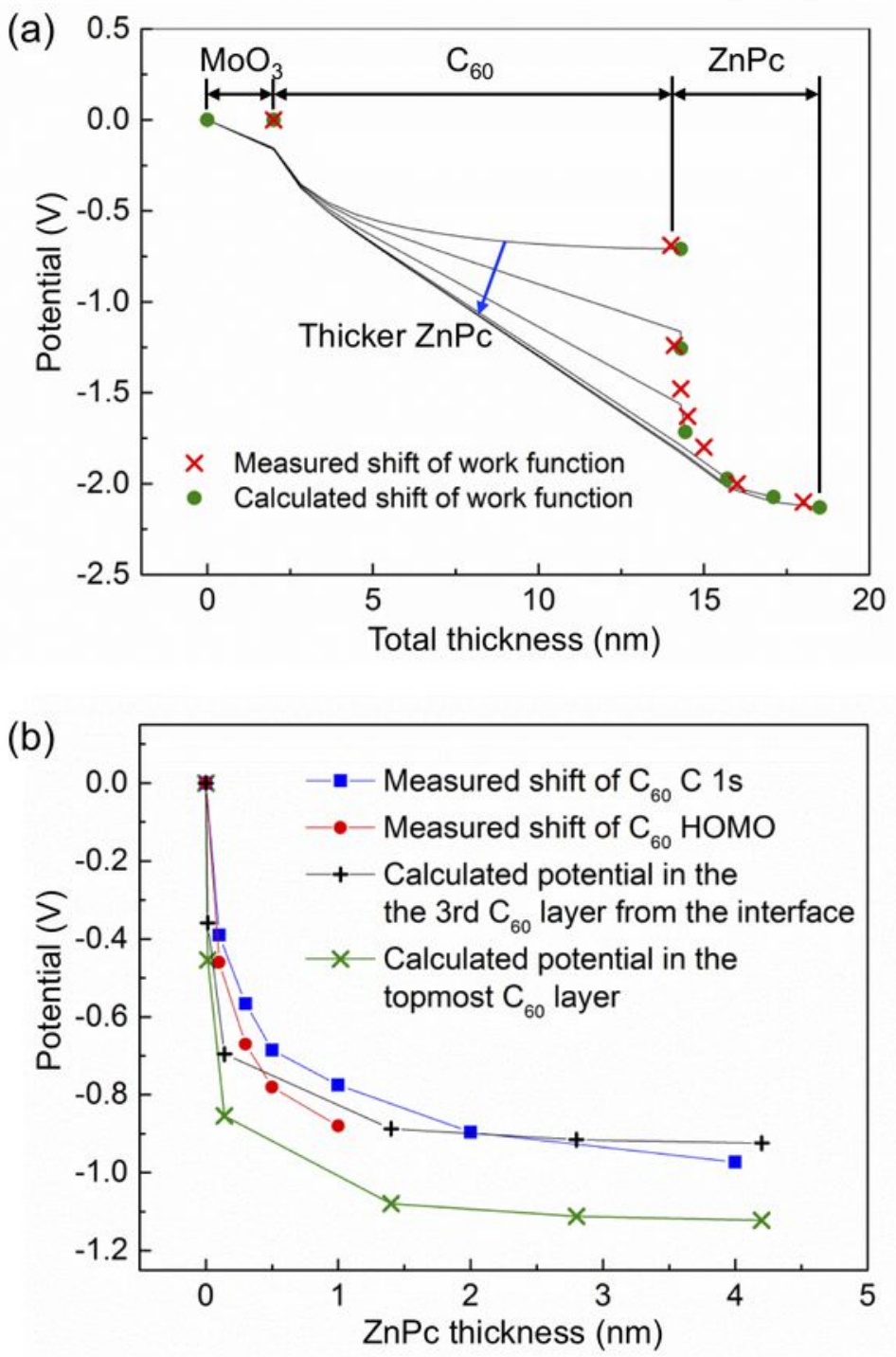

(c)

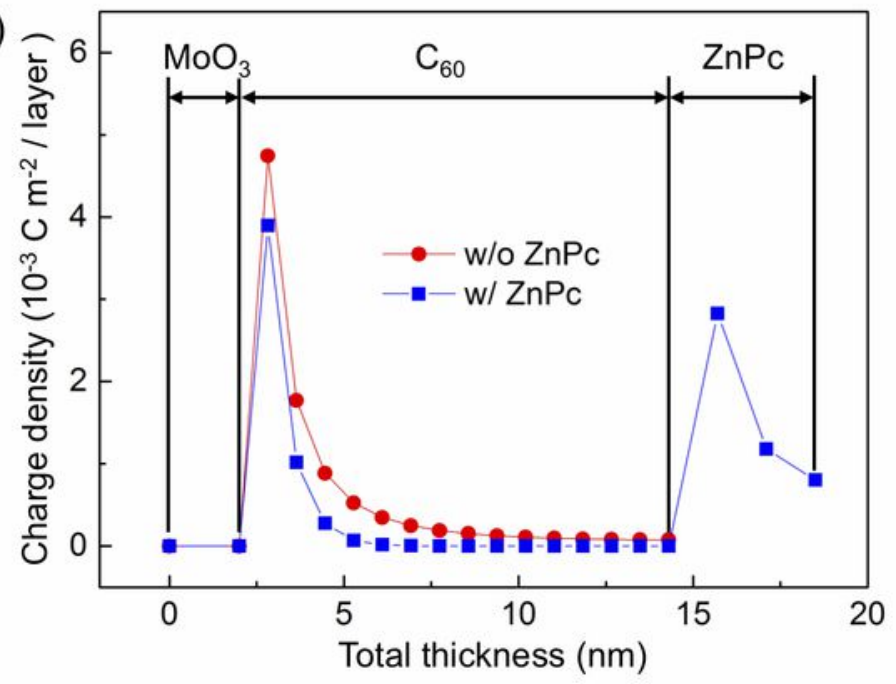




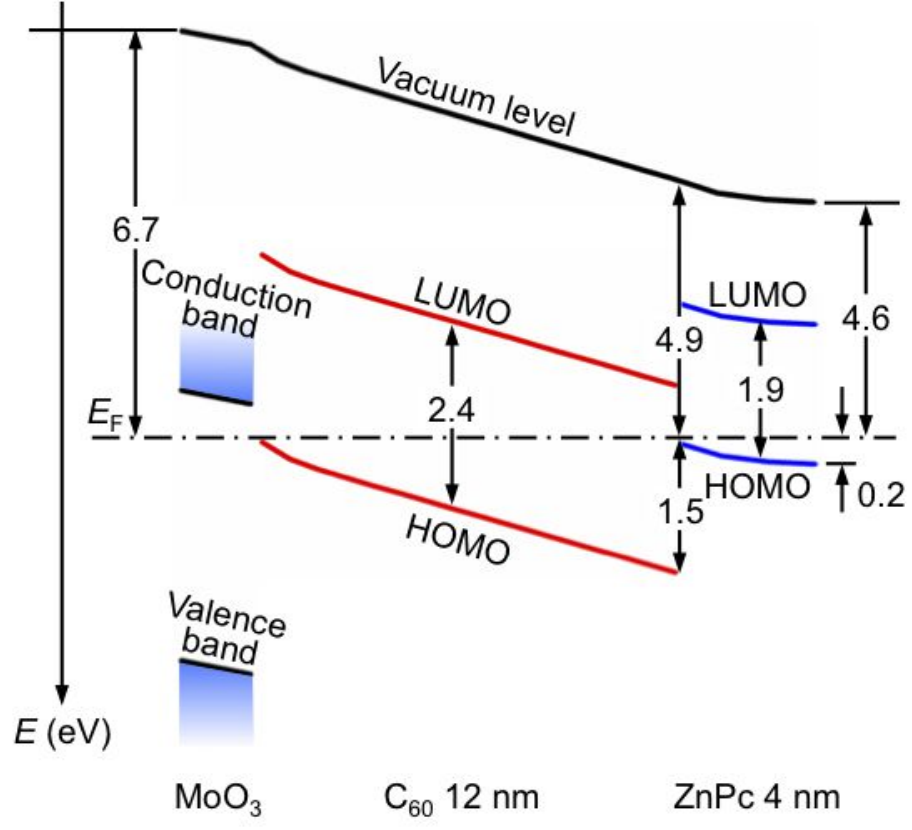

